\title{
Políticas públicas para inovação: um estudo da metodologia de gestão da inovação na indústria em Alagoas
}

\section{Public policies for innovation: a study of innovation management methodology in the industry in Alagoas}

\author{
Danielle Ferreira de Melo Mestre em Administração Pública. Universidade Federal de Alagoas (UFAL) - Brasil. \\ melo.daniy@gmail.com. \\ Luciana Peixoto Santa Rita Doutora em Administração. Universidade Federal de Alagoas (UFAL) - Brasil. \\ lupsanrita@gmail.com \\ Reynaldo Rubem Ferreira Junior Doutor em Economia. Universidade Federal de Alagoas (UFAL) - Brasil. rrfj@uol.com.br \\ Josealdo Tonholo Pós-Doutor em Eletroquímica. Universidade Federal de Alagoas (UFAL) - Brasil. \\ tonholo@gmail.com \\ Eliana Maria de Oliveira Sá Mestre em Educação. Federação da Indústria do Estado de Alagoas (FIEA) - Brasil. \\ eliana.sa@fiea.org.br
}

\begin{abstract}
RESUMO
A importância direcionada ao tema da gestão da inovação cresce no âmbito do desenvolvimento das políticas públicas. Este estudo tem como objetivo geral analisar a relação entre o uso de instrumentos de políticas públicas de inovação e a Gestão da Inovação (Gl) no setor industrial do estado de Alagoas. Especificamente, almeja analisar o desempenho das indústrias em relação ao desenvolvimento de uma metodologia de Gl, examinar a maturidade de empresas industriais quanto às práticas de Gl e mapear os instrumentos de políticas públicas acessados por essas indústrias. Dessa forma, utilizou-se, quanto aos objetivos, a pesquisa exploratória e descritiva, com a abordagem qualiquantitativa. Trata-se de um estudo realizado com 19 (dezenove) indústrias participantes do projeto de Gl, tendo como unidades de investigação indústrias. Sobre os resultados encontrados, a participação no projeto e a metodologia de Gl utilizada possibilitou novas práticas nas unidades estudadas. Identificou-se que há uma relação indireta entre o acesso aos instrumentos de políticas públicas e a Gl nas empresas. Constatou-se, ainda, que o projeto contribuiu para o entendimento da importância da Gl. Por fim, os resultados apontaram que o acesso das indústrias aos instrumentos de políticas públicas, do total das dezenove empresas pesquisadas, é limitado, pois apenas três utilizaram os instrumentos mencionados.
\end{abstract}

Palavras-chave: Políticas Públicas. Inovação. Gestão da Inovação.

\begin{abstract}
The importance of innovation management is growing in the context of public policy development. This study aims to analyze the relationship between the use of public policy instruments for innovation and Innovation Management (IM) in the industrial sector of the state of Alagoas. Specifically, it aims to analyze the performance of industries in relation to the development of an IM methodology, examine the maturity of industrial companies in relation to IM practices, and map the public policy instruments accessed by these industries. For that purpose, exploratory and descriptive research was used, with a qualitative and quantitative approach. The study was conducted with 19 (nineteen) industries participating in the IM project, with industries as research units. Regarding the results, the participation in the project and the IM methodology used enabled new practices in the studied units. It was identified that there is an indirect relationship between access to public policy instruments and IM in companies. It was also found that the project contributed to the understanding of the importance of IM. Finally, the results showed that the access of industries to public policy instruments in the nineteen companies surveyed is limited, since only three used the instruments mentioned. Keywords: Public Policy. Innovation. Innovation Management.
\end{abstract}




\section{INTRODUÇÃO}

A literatura tem investigado muitos aspectos sobre a abordagem das políticas de ciência, tecnologia e inovação (OECD, 2016; ROGGE; REICHARDT, 2016; TURCHI; MORAIS, 2017; CASTELA; FERREIRA, F.; FERREIRA J.; MARQUES, 2018; EDMONDSON; KERN; ROGGE, 2018; PARANHOS; CATALDO; PINTO, 2018; KERNA; ROGGE; HOWLETTD, 2019) e destaca a necessidade de esforços e ações com foco na inovação, seja em um ambiente sistêmico ou voltadas as empresas, envolvendo institutos de pesquisa, universidades e outras instituições de apoio ao ecossistema de inovação.

As políticas de inovação, em boa medida, são consequências do mix de políticas de Ciência, Tecnologia e Inovação (CT\&l). A formulação dessas políticas leva em consideração o fato de que o conhecimento exerce um importante papel no avanço econômico e que a inovação se trata de algo complexo e sistêmico (OECD, 2016).

Em linha com os modelos de política industrial, as medidas mais especificas do mix de políticas de inovação no Brasil estiveram associadas e estão relacionadas com incentivos ao investimento sob a forma de recursos não reembolsáveis, redução de impostos e tarifas ou apoio financeiro, mediante empréstimos e recursos concessionais aos setores-alvo, requerimentos de desempenho, zonas econômicas especiais (incluindo, cluster, incubadoras e parques tecnológicos), facilitação de investimento, investidor-alvo, entre outras.

Dutta, Lanvin e Wunsch-Vicent (2015) ressaltam o posicionamento de países em desenvolvimento e emergentes que, progressivamente, vêm projetando políticas para fins de aumento da capacidade de inovar. Essas configuram-se distintivamente consoante as necessidades identificadas pelo próprio país e seu impacto também sofre variações mesmo em nações com nível de desenvolvimento semelhantes.

Conforme aponta Negri (2017), o país alcançou, ao longo das últimas duas décadas, a implementação de um conjunto de políticas nas áreas de Ciência, Tecnologia e Inovação (CT\&l) , fundos setoriais, incentivos fiscais, medidas regulatórias etc. Destaca, contudo, a semelhança de parte delas com políticas de fomento à inovação adotadas mundialmente, mas ocasionando resultados modestos do ponto de vista da competitividade setorial.

Tidd e Bessant (2015) afirmam que as empresas inovadoras crescem duas vezes mais rápido do que aquelas que não desenvolvem inovações. As bem-sucedidas na Gestão da Inovação (Gl) refletem desempenho superiores em termos de crescimento, resultados financeiros e geração de emprego. Entretanto, a Gl não é algo simples, conforme aponta Canongia et al. (2004), pois requer esforços que reúnam os métodos e instrumentos imprescindíveis à garantia da capacidade de inovar das empresas. Mesmo atuantes em meio às forças de mercado, as empresas demonstram limitações para desenvolver atividades de inovação.

A literatura está repleta de estudos empíricos (LIYANAGE; GREENFIELD; DON, 1999; MILLER, 2001; BERKHOUT et al., 2006; DE MARTINO; MAGNOTTI, 2018) que descrevem a Gestão da Inovação (GI) como elemento impulsionador na consolidação de processos sistêmicos de inovação no ambiente empresarial, promovendo o fluxo de conhecimento, desenvolvimento, cooperação com outras instituições e, consequentemente, contribuindo para o fortalecimento dos sistemas de inovação e do desenvolvimento econômico.

Em particular, o artigo não aponta resultados comuns às pesquisas em estado da arte análogas, ilustrando a existência de uma metodologia de gestão da inovação robusta, mas analisa as metodologias de gestão de inovação tradicionais, pois se trata de um estudo em um Estado com uma indústria pouco diversificada e com baixa densidade tecnológica.

O artigo baseia-se em duas premissas de estudo. A primeira define a gestão da inovação em uma visão da abordagem tradicional (mainstream), conforme Cooper (1994), Berkhout et al. (2006), Tigre (2006), Tidd et al. (2008), Paladino (2010), Zawislak et al. (2013) e Tidd; Bessant (2015), apesar de não se refutar o papel difusor de novas tecnologias das grandes indústrias sobre a gestão da inovação. Entretanto, examina-se em que medida as práticas de fomento e oferta de recursos para as atividades inovativas são suficientes para compensar o baixo esforço inovativo das pequenas empresas. A segunda aponta que o objetivo de uma metodologia de gestão da inovação, mesmo em uma região com grandes fragilidades na composição das 
atividades econômicas, é promover a geração e difusão de inovações, além de ser configurado inicialmente como um estudo exploratório.

Deste modo, como justificativa do estudo, destaca-se que, ao longo dos últimos anos, constatou-se que não é suficiente e apropriado que a dinâmica do desenvolvimento econômico se baseie no surgimento espontâneo de empreendimentos inovadores. Torna-se necessário investir e permitir o acesso de políticas de inovação no setor empresarial, fomentando assim os ambientes de inovação e negócios inovadores (SANTA RITA; FERREIRA JÚNIOR; SÁ, 2013). A aplicação de metodologias de gestão da inovação vem sendo condição para o alcance de desempenho em muitas regiões e países.

Para delimitar e aprofundar estas reflexões iniciais, este artigo pretende aprofundar o entendimento acerca da seguinte questão: qual seria a relação entre o uso de instrumentos de políticas públicas de inovação e a Gestão da Inovação (GI)? Assim, objetiva-se analisar a relação entre o uso de instrumentos de políticas públicas de inovação e a Gestão da Inovação $(\mathrm{Gl})$ no setor industrial do estado de Alagoas. Especificamente, almeja analisar o desempenho das indústrias em relação ao desenvolvimento de uma metodologia de $\mathrm{Gl}$, examinar a maturidade de empresas industriais quanto às práticas de $\mathrm{Gl}$ e mapear os instrumentos de políticas públicas acessados por essas indústrias.

A estrutura do artigo está organizada da seguinte forma: a seção 2 apresenta o marco conceitual e teórico; a seção 3 descreve a metodologia utilizada nos critérios quantitativos e qualitativos para avaliar esse processo, visto que a análise é fortemente orientada empiricamente, uma vez que se baseia em uma metodologia de gestão da inovação. A análise com resultados e discussão é efetuada na seção 4 e abrange três subseções. A seção 5 sintetiza os principais resultados e apresenta as conclusões retiradas da análise.

\section{ABORDAGEM TEÓRICA}

A extensa literatura tem investigado muitos aspectos (FREEMAN, 1987; LUNDVALL, 1992; NELSON, 1993; ANDREONI; SCAZZIERI, 2013; AVELLAR E BOTELHO, 2015; KAHN, 2018; TEZA et al., 2018; COADA et al., 2019) como a atividade de inovar obteve destaque, desde Schumpeter ao tratar do processo de "destruição criativa" em uma sociedade capitalista até os teóricos neoschumpeterianos que ressaltaram a inovação como fator impulsionador para o desenvolvimento econômico.

\subsection{Inovação, Gestão da Inovação e Metodologias de Gestão da Inovação}

Schumpeter (1982) apontou uma base conceitual sobre inovação diferenciando invenção, inovação e difusão. Como tal, a invenção é o desenvolvimento de um processo ou produto com sentido de explorar comercialmente a descoberta, até o momento, não realizada. A inovação é a transformação da invenção em um produto, processo ou modelo organizacional comercialmente e mercadologicamente rentáveis.

Assim, da análise schumpeteriana, a busca por vantagens competitivas pelas firmas existentes é o motor da concorrência e o grande alavancador do investimento em atividade de P\&D. O lucro é o grande motivador para as firmas aplicarem processos inovativos, pois a inovação resulta em lucro extraordinário. Portanto, para reduzir a incerteza reduzida, as firmas comportam-se com rotina que aponte ações baseadas no conhecimento acumulado ao longo da história, resultando em regularidade nas inovações. Sob a perspectiva de Dosi (1988, p. 222), a inovação "diz respeito à busca e descoberta, experimentação, desenvolvimento, imitação e adoção de novos produtos, novos processos de produção e novos arranjos organizacionais".

$O$ debate acadêmico, em torno do fenômeno da inovação, tem se concentrado no conceito de capacidade de inovação (LAWSON; SAMSON, 2001; CALANTONE; CAVUSGIL; ZHAO, 2002; LIN, 2007; SAUNILA, 2019). A capacidade de inovação pode ser definida como o potencial para criar produtos ou conhecimentos novos e valiosos (ZHENG; LIU; GEORGE, 2010). Por outro lado, Lawson e Samson (2001) conceituam a capacidade de inovação como a possibilidade em transformar conhecimento e ideias em produtos, processos e sistemas. Neste contexto, a capacidade de inovação é determinante para as empresas de pequeno e médio porte, visando competir com seus concorrentes. As evidências empíricas sobre a capacidade de inervação no 
contexto das pequenas empresas se desenvolveram sob duas vertentes de pesquisa, sendo uma a que estuda os determinantes da capacidade de inovação e outra a que estuda as consequências sobre a capacidade de inovação.

Canongia et al., (2004) apontam para a implementação da gestão da inovação em dois níveis. $O$ primeiro interno às organizações, abrangendo processos de reconhecimento e construção de competências, disseminação de conhecimento, identificação de oportunidades e implementação de estratégias que estejam alinhadas com a produção e a P\&D. E o segundo externo à organização, relacionado as habilidades de contratação e venda de competências, captação de recursos financeiros e interações com outras instituições - como clientes, fornecedores, universidades, centros de pesquisa, ou ainda concorrentes - que possam contribuir de alguma forma no processo de inovação.

Sobre a implantação da gestão da inovação nas empresas, Bisneto e Lins (2015) identificam que o processo ainda é pouco estruturado. Os autores ressaltam que, além de formalizado, o processo deve estar alinhado às estratégias competitivas da organização, e direcionado ao mercado e aos clientes. Alguns tópicos comuns também são citados por Freitas Filho (2013), sendo a presença do planejamento estratégico, a continuidade da estruturação do processo de $\mathrm{Gl}$ e a geração de resultados, mediante o estabelecimento de uma cultura voltada a inovação. Freitas, Campos e Souza (2015) destacam, a partir de estudos, o papel relevante do planejamento estratégico para os resultados das empresas quando desdobrado em todas as áreas visando entregar inovação em produtos, processo, pessoas e cultura.

Existem muitas maneiras de mensurar o grau de inovação e diferentes são os modelos de metodologias de gestão da inovação encontrados na literatura. Faz-se necessário, contudo, a adaptação de um modelo que seja implantado com ferramentas que permitam gerir a inovação de forma sistemática e sistêmica (CNI, 2010), sendo assim avaliado seu ambiente interno e suas necessidades.

A literatura tem apresentado diversos modelos de inovação, sendo algumas metodologias consolidadas e que possibilitam mensurar a capacidade inovativa de uma empresa (CLARK; WHEELWRIGHT, 1992; COOPER, 1994; Docherty, 2006; HANSEN; BIRKINSHAW, 2007; TIDD; BESSANT; PAVITT, 2008; CNI, 2010; INSTITUTO EUVALDO LODI DE SANTA CATARINA, 2011; BARBIERI; ALVARES, 2016; ZEN et al., 2017).

De forma geral, as metodologias desenvolvidas por Clark e Wheelwright (1992) bem como por Cooper (1994) correspondem aos modelos de referência para a gestão da inovação, reconhecendo que as intervenções exibem diferentes graus de compatibilidade com os objetivos do mercado. A metodologia de Cooper (1994), Stage-Gate, é direcionada à condução de projetos para o desenvolvimento de novos produtos por meio de um modelo gráfico em várias etapas, que alcança desde a geração da ideia até seu lançamento e etapas posteriores. Por sua vez, a metodologia de Clark e Wheelwright (1992), Funil de Desenvolvimento, abrange três etapas diferente, sendo a primeira desenhada pela ampliação da boca do funil. Os autores sublinham que a organização possui uma base de conhecimento com acesso a informações que possibilitam o surgimento de novas ideias e produtos. A segunda etapa busca diminuir o centro do funil, ou seja, após geradas e analisadas várias ideias, o corpo organizacional foca esforços e recursos nas ideias mais valorosas à organização.

Outra metodologia bastante utilizada, pincipalmente nos modelos de ecossistema de inovação, é a Docherty (2006), conhecida como funil de inovação aberta, em que as organizações procuram soluções externas para suas demandas, por meios de universidades, startups e outras fontes disponíveis para serem utilizadas de forma colaborativa. Nessa metodologia, é possível que as empresas adquiram inovações externas que já estão no mercado ou realizem transferência de tecnologia. A metodologia do processo de gestão da inovação desenvolvida pelo Instituto Euvaldo Lodi - IEL (2018) foi criada com o propósito de fomentar o desenvolvimento de competências empresariais, visando aumentar a capacidade inovadora das empresas por meio do envolvimento da alta direção e colaboradores da organização, integração das áreas e uso de ferramentas adequadas do processo de gestão da inovação. O Instituto aborda o processo integralmente, além de especificar as etapas da gestão da inovação quanto ao interesse e ao nível de maturidade existente.

Desta feita, além dos modelos mencionados, vale salientar que outras metodologias vêm sendo aplicadas e customizadas. Contudo, observa-se que das metodologias clássicas até as mais contemporâneas sempre há uma evolução no sentido de não focar apenas na geração de ideias e condução dos processos de 
inovação, como no caso das clássicas, mas também à promoção de um ambiente favorável a Gl, com fomento da cultura organizacional.

\subsection{Políticas Públicas de Ciência, Tecnologia e Inovação (CT\&l)}

Historicamente, segundo Schot e Steinmueller (2018), as políticas de inovação se dividem em três momentos, sendo o primeiro direcionado à inovação para o crescimento econômico, conjugando o potencial da ciência e da tecnologia para o fomento sociotécnico aliados aos sistemas, orientados para a produção, consumo em massa e melhoria na produtividade dos fatores. Essa fase prevaleceu até a o fim da Segunda Guerra, quando a intervenção do Estado se intensificou. O segundo momento foi marcado pela tipologia dos sistemas nacionais de inovação que surgiu durante a década de 1980 para abordar algumas das consequências da competição internacional e da globalização. O terceiro surgiu em 2015, sendo determinado pelo movimento do uso da ciência e da tecnologia para responder às necessidades sociais e abordar as questões da sustentabilidade e sociedades inclusivas. A evolução das políticas de inovação se deu na combinação de políticas de ciência e tecnologia, direcionando o foco da política para a interação entre instituições, os processos de geração de conhecimento e sua disseminação e aplicação (OECD, 2016).

$\mathrm{Na}$ literatura recente sobre política de inovação, instrumentos sistêmicos têm sido propostos para complementar as políticas de inovação mais tradicionais (WIECZOREKE; HEKKERT, 2012; BORRÁS; EDQUIST, 2013). Ademais, estudos sobre políticas reforçando a ideia de combinação de políticas em vez de instrumentos de política (SCHOT; STEINMUELLER, 2018). De fato, o tema "policy mix" tem recebido crescente interesse em estudos de inovação nos últimos cinco anos, com várias contribuições (EDMONDSON; KERN; ROGGE, 2018; KERNA; ROGGE; HOWLETTD, 2019) em que a combinação de instrumentos interagem para influenciar a quantidade e a qualidade de investimentos em P\&D nos setores público e privado. A abordagem de política sobre "policy mix" reconhece a natureza "path-dependent" da elaboração de políticas e através das quais as combinações de políticas evoluem ao longo do tempo. Edmondson, Kern e Rogge (2018) destacam a coevolução das combinações de políticas e sistemas sociotécnicos ao longo do tempo.

Jaumotte e Pain (2005) identificaram, a partir de estudos, cinco questões principais inseridas em políticas destinadas a lidar com falhas de mercado no processo de inovação: (1) incentivos fiscais para a P\&D no setor privado; (2) financiamento de organizações públicas de pesquisa e medidas para melhorar sua interação com o setor privado; (3) normatização da propriedade intelectual; (4) a disponibilidade de financiamento; e (5) disponibilidade de recursos humanos qualificados para a ciência e a tecnologia.

Para a CNI (2017), políticas de inovação bem-sucedidas têm seu núcleo composto por duas vertentes essenciais, ou seja, realizar esforços para melhorar as condições básicas para a inovação, abrangendo o ambiente de negócios e o acesso a financiamentos e desenvolver políticas de inovação que compreendam não só os atores da inovação, mas também os vínculos entre eles. Nesse contexto, um sistema jurídico e regulatório em nível de conformidade maior ou menor pode ser o responsável pelos processos de inovação obterem êxito ou fracassarem (CNI, 2018).

Nos últimos vinte anos, o Brasil obteve avanços significativos com a implementação de um conjunto de políticas direcionadas a CT\&I. A criação dos fundos setoriais por volta de 1990, a Lei no 10.973, a Lei no 11.196 e o Plano Inova Empresa constituem exemplos dessas políticas (TURCHI; MORAIS, 2017). Os incentivos ao desenvolvimento tecnológicos passam a receber maior atenção por volta de 1990 com o desenvolvimento de instrumentos de incentivo fiscal e mecanismos de financiamento (FINEP, 2018; GOMES et al., 2015; SALERNO; KUBOTA, 2008). Em 1993, O Programa de Desenvolvimento Tecnológico Industrial ou Agropecuário (PDTI/PDTA) foi criado através da Lei n..$^{\circ} .661$, o objetivo era estimular o setor privado a investir em inovação através da dedução do imposto de renda (IR) e do crédito fiscal (AVELLAR et al., 2008). No entanto, devido a sua complexidade burocrática, a lei foi substituída pela Lei no 11.196, que ampliou os incentivos fiscais e melhorou os mecanismos de acesso aos benefícios (KANNEBLEY JR.; PORTO, 2012, p. 3).

Conforme apontam Kannebley Jr. e Porto (2012), em termos de propósito e recursos, os instrumentos de políticas de inovação de maior destaque no âmbito da Política Industrial Tecnológica e de Comércio Exterior 
(PITCE) foram a subvenção econômica para empresas e incentivos ficais à inovação estabelecidos na Lei no 10.973 e na Lei no 11.196.

A Lei no 10.973 determina parâmetros de "incentivo à inovação e à pesquisa científica e tecnológica no ambiente produtivo, com vistas à capacitação tecnológica, ao alcance da autonomia tecnológica e ao desenvolvimento do sistema produtivo nacional e regional do País" (BRASIL, 2004). Turchi e Morais (2017) apontam os benefícios trazidos pela lei, ao regulamentar a parceria entre pesquisadores de instituições públicas e empresas para desenvolver projetos de pesquisa, e a comercialização da propriedade intelectual resultante do projeto, houve encorajamento dos setores públicos e privados no compartilhamento de recursos financeiros e humanos, além de tornar mais simples a cooperação entre universidades, institutos de pesquisa e empresas privadas.

Ademais, observa-se que o marco regulatório do país vem passando por mudanças com o propósito de aperfeiçoar as condições institucionais indispensáveis à ascensão da inovação, destacando-se a Lei no 13.243. A lei traz melhorias incorporadas na Lei $n^{\circ} 10.973$, além de outras que possibilitam ao Estado atuar mais facilmente na promoção de negócios inovadores, seja com uso de instrumentos mais flexíveis no relacionamento com empresas privadas, seja pela fixação de normas que entregam maior liberdade e segurança nas relações entre empresas e institutos públicos de pesquisa (BRASIL, 2004; MCTIC, 2016).

Apesar desse progresso, o país ainda possui um marco regulatório de inovação incompleto e ambíguo que leva a distorções, demandando correção e simplificação dos processos de modo a promover um ambiente mais propício aos negócios, serviços e à indústria. Mesmo nesse contexto, diversas empresas alavancaram seu desempenho e competitividade (CNI, 2018).

\section{METODOLOGIA}

Descreve-se a metodologia da pesquisa. Assim, este estudo tem natureza aplicada, objetivos exploratório e descritivo, com abordagem qualiquantitativa. Quanto à natureza de pesquisa, foi uma pesquisa aplicada com o objetivo de gerar conhecimentos que pudessem ser utilizados na solução de problemas específicos na realidade e nos interesses locais (HAIR et al., 2005; PRODANOV; FREITAS, 2013).

Tratando-se da classificação de pesquisa utilizada na análise dos dados, empregaram-se a quantitativa e a qualitativa, respectivamente. A quantitativa para atender ao objetivo específico em examinar a maturidade das indústrias quanto às práticas de $\mathrm{Gl}$ a partir de aplicação de teste não paramétrico. A qualitativa para atender o objetivo específico de estudar a relação entre o uso de instrumentos de políticas públicas de CT\&l e a Gl.

No estudo, as empresas foram investigadas com base na metodologia de gestão da inovação do IEL (2018), sendo submetidas ao projeto de GI nela preconizado. A seleção das empresas, objeto da pesquisa, teve como ponto de partida as 19 (dezenove empresas) atendidas pelo "Projeto de Gestão de Inovação para Micro e Pequenas Empresas Industriais", conforme termo de adesão das empresas ao convênio de cooperação técnica no 46/2014 CNI/FIEA. Outros pré-requisitos de seleção foram: ser micro e pequeno porte (faturamento de até 3,6 milhões em 2015) e ser classificada na atividade principal de Indústria. O critério final baseou-se na concordância da empresa em participar do estudo e na disponibilidade em receber uma pesquisadora para realização dos diagnósticos. Os dezenove casos selecionados representaram, de certa forma, o grupo de atores do setor produtivo participantes da aplicação da metodologia do IEL (2018).

Destaca-se que a pesquisa aconteceu concomitante ao desenvolvimento do projeto de $\mathrm{Gl}$, mediante aplicação dos instrumentos de coletas descritos na seção 3.1. As visitas técnicas do projeto aconteceram no período de agosto de 2017 até dezembro de 2018, tempo médio de doze meses, nas quais foram realizados diagnósticos, atividades e sensibilizações para a Gl.

\subsection{Instrumento de Coleta}

Os instrumentos de coleta utilizados foram os formulários, aplicados com objetivo de analisar, a partir da abordagem quantitativa, a gestão da inovação e a maturidade das empresas industriais na $\mathrm{Gl}$ e, 
posteriormente, mapear os instrumentos de políticas públicas acessados pelas empresas industriais alagoanas.

O primeiro formulário integra a metodologia de GI do Instituto Euvaldo Lodi. A aplicação desse formulário aconteceu em dois momentos distintos: T0 - antes do início do projeto com a finalidade de verificar a $\mathrm{Gl}$ e a maturidade das indústrias em relação a $\mathrm{Gl}$, mapeando as principais dificuldades e pontos a serem trabalhados com maior ênfase durante as consultorias; $\mathrm{T} 1$ - depois de finalizado o projeto, com o objetivo propor comparaç̃es com os dados coletados anteriormente e verificar s progressos nas áreas desenvolvidas.

O tempo médio do intervalo entre os momentos foi de doze meses. A aplicação da pesquisa foi realizada durante as visitas técnicas. $O$ formulário respondido abrangia variáveis as quais possuem quatro itens. A avaliação desses itens aconteceu mediante a seleção de uma posição em uma escala de Likert de 7 pontos. A escala possui uma variação entre os rótulos da posição mínima (1) e máxima (7). Os rótulos de cada questão apresentavam informações que descrevem as características das posições, possibilitando ao respondente identificar aquela que mais se adequava à realidade do negócio. As variáveis estudadas foram: Cultura de inovação: Aprendizagem organizacional: Marketing e Relacionamento com o ambiente externo. O segundo formulário foi elaborado com a finalidade de mapear, após verificação dos instrumentos de políticas públicas de fomento à inovação disponíveis em Alagoas, quais as empresas industriais tiveram acesso no período anterior ao desenvolvimento do Projeto de Gestão da Inovação. Esse formulário foi inicialmente validado com duas empresas e reformulado a partir das observações pontuadas pelas empresas. $A$ priori, os documentos utilizados nesta etapa foram: (1) a Lei Federal 13.243, instituída em 11 de janeiro de 2016 e (2) a Estratégia Nacional de Ciência, Tecnologia e Inovação. Posteriormente, os sites eletrônicos das agências de fomento - CNPq, Finep, BNDES e EMBRAPII, em âmbito federal, a FAPEAL e a Desenvolve, em âmbito estadual - foram acessados.

\subsection{Tratamento dos dados}

O tratamento dos dados foi dividido em dois momentos. O primeiro, mediante abordagem quantitativa, esteve direcionado a analisar o desempenho das indústrias na Gl, para isso, foram utilizadas a estatística descritiva (médias) e a estatística não paramétrica (teste de hipóteses). Posteriormente, a análise da relação entre o acesso aos instrumentos de políticas públicas e o desempenho na Gl compôs a segunda etapa do tratamento dos dados, desenvolvida a partir da abordagem qualitativa.

A análise do desempenho das indústrias na Gl foi construída de modo mais detalhado a partir das médias atribuídas a cada um dos itens que compõem as variáveis. Neste estudo, aplicou-se a média.

Ainda no primeiro, aplicou-se também o teste estatístico não paramétrico com a finalidade de verificar, de modo generalizado, o progresso obtido pelas indústrias em cada uma das variáveis. Hair Jr et al (2005) descreve dois grupos principais de procedimentos estatísticos: paramétricos e não paramétricos. Este é utilizado quando os dados são mensurados por meio de uma escala nominal ou ordinal, não sendo possível supor que há uma distribuição normal.

Com base nas variáveis da $\mathrm{Gl}$, as seguintes hipóteses nulas e alternativa foram estabelecidas: $\mathrm{H} 0$ condições não se diferem em termos de desempenho na $\mathrm{Gl}$ e H1 - condições se diferem em termos de desempenho na Gl.

Sobre o nível de significância estatística, partiu-se do pressuposto de que haveria comportamentos distintos das indústrias para as variáveis em função da participação no projeto de $\mathrm{Gl}$ - valor estatisticamente significativo a um nível de probabilidade associada de $p<0,05$. O valor $p$ é a probabilidade de obter o padrão de resultados encontrados no estudo, caso não exista o relacionamento entre as condições de interesse (DANCEY; REIDY, 2013).

O teste estatístico aplicado neste estudo foi selecionado com base no "Diagrama de fluxo" para orientar a escolha do teste mais adequado para o delineamento de um estudo" proposto por Dancey e Reidy (2013). A partir do diagrama, o fluxo seguido foram duas variáveis (situação antes do desenvolvimento do projeto e situação após o desenvolvimento do projeto); busca por diferenças entre condições; delineamento intraparticipantes (mesmos participantes nas duas condições estudadas); teste t para amostra relacionadas. 
Após identificado o teste $t$ a partir do diagrama, verificou-se o seu teste correspondente para a estatística não paramétrica. Dessa forma, foi estabelecido para ser aplicado neste estudo o teste Wilcoxon para amostras relacionadas. $O$ teste Wilcoxon é usado quando os participantes são os mesmos nas duas condições estudadas (DANCEY; REIDY, 2013).

Por fim, a segunda parte da análise dos resultados, procurou identificar a relação entre o acesso aos instrumentos de políticas públicas e o desempenho na Gl. Essa análise ocorreu a partir das percepções obtidas na coleta coma a aproximação com os gestores das indústrias em todo o desenvolvimento do projeto de $\mathrm{Gl}$, em reuniões, aplicação de diagnósticos e atividades colaborativas.

\section{RESULTADOS E DISCUSSÃO}

Arrolaram-se os dados relativos às dimensões e fatores da pesquisa. Em um primeiro momento, a análise individual dos fatores examinou o conteúdo, sem a exigência de uma análise do problema e suas devidas associações, utilizando-se para isso estatística descritiva.

Em seguida, registraram-se as associações no problema pesquisado, sendo apresentados a análise comparativa e os testes não paramétricos, sendo a primeira corresponde à análise do desempenho das empresas no que tange ao desenvolvimento do projeto de $\mathrm{Gl}$, a segunda consistiu em examinar a relação entre o uso de instrumentos de políticas de inovação e a Gl.

\subsection{Desempenho das indústrias na GI}

A primeira área do desempenho da $\mathrm{Gl}$, inovações nas empresas, diz respeito às mudanças planejadas decorrentes de atividades realizadas com a finalidade de ampliar o desempenho. Assim, com base nesses aspectos, estiveram inseridas nessa área as variáveis "Cultura de inovação" e "Aprendizagem organizacional".

A segunda área corresponde à demanda que influencia a atividade de inovação de várias maneiras. Dessa forma, a variável "Marketing para a inovação" foi utilizada para fins da análise da referida área.

A interação com outras empresas corresponde à terceira área de estudo, sua importância reside no fato da mesma ser uma fonte de conhecimento e de tecnologias para as atividades inovativas. Assim, a variável "Relacionamento com o ambiente externo" esteve relacionada com a última área.

O estudo possibilitou identificar, a partir de uma escala de sete pontos, a situação em que a empresa se encontrava antes do desenvolvimento do projeto de gestão da inovação e o avanço que obteve após seu término. De uma maneira geral, observa-se os níveis de maturidade das empresas em relação aos aspectos da capacidade de planejamento das atividades e da sistematização dos processos.

A figura 1 corresponde à escala utilizada na pesquisa. Para fins de análise, esta foi dividida em três níveis: o nível baixo é compreendido pelo intervalo de 1 até 3 pontos, o nível intermediário de 3,1 até 5 pontos, e o mais alto 5,1 até 7 pontos.

Figura 1 - Níveis da escala gráfica

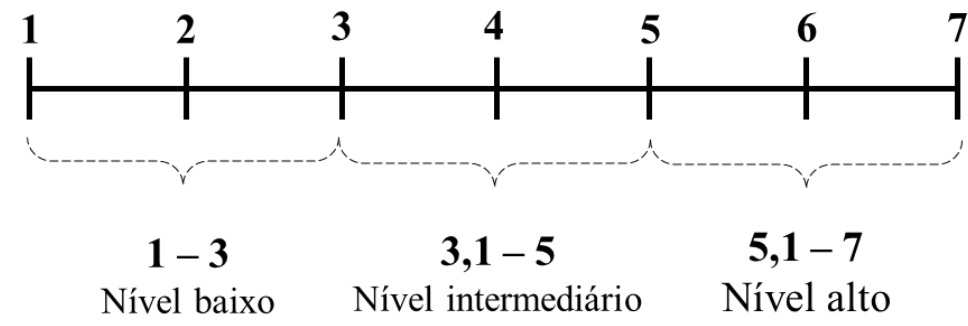

Fonte: Elaborada pelos autores (2019) 


\subsubsection{Inovação na empresa}

\section{a) Cultura de inovação}

Assim, a variável "Cultura de inovação" é compreendida por quatro itens: a) planejamento da mudança, b) estímulo à autoconfiança, c) estímulo à novas ideias e d) tomada de risco. Os resultados obtidos podem ser observados no gráfico 1.

Dessa forma, a partir do item "Planejamento da mudança" buscou-se verificar os estímulos praticados pelas empresas para que os funcionários investissem parcela de seu tempo no planejamento do processo de mudança. As indústrias que sinalizaram o nível mais baixo (1) concordaram sobre seu planejamento ser realizado somente de forma eventual e baseado em erros cometidos no passado, diferente das situadas no nível mais alto (7) que costumam exercer a função de planejar de modo sistêmico, decorrente de objetivos estratégicos para o longo prazo.

Sobre o momento anterior a execução do projeto de Gl, os resultados apontam uma média de 2,3. Muitas empresas participantes não concediam a devida importância para a atividade de planejar, situando-se principalmente nos níveis mais baixos da escala. As práticas aconteciam de forma intuitiva, embasada na experiência de quem as executava, acarretando quase sempre em falhas, atrasos ou na desistência de implementar a ideia.

A intenção do item "Estímulo à autoconfiança", que também compreende à variável cultura de inovação, foi avaliar o nível das empresas no que diz respeito à prática de estímulos a autoconfiança de seus funcionários para que adotem iniciativas próprias. No nível mais baixo da escala, situam-se as empresas que direcionam estímulos de maneira eventual e apenas para os principais líderes. Em contraponto, àquelas situadas no nível mais alto estimulam sistematicamente todas as pessoas, mediante níveis de autonomia estabelecidos.

Mais da metade das indústrias encontrava-se nos níveis mais baixos, quando avaliadas no momento anterior a sua participação no projeto.

O item "Estímulo a novas ideias" diz respeito a participação estimulada pela empresa dos colaboradores na sugestão de novas ideias para produtos (bens ou serviços) ou processos. A localização no nível mais baixo indica que esse estímulo acontece de modo eventual e informal, já no nível mais alto o processo é sistêmico e acontece mediante ferramentas de incentivo, avaliação e reconhecimento. A maior parte das empresas não possuía instrumentos formais e contínuos que incentivassem a participação dos colaboradores no fornecimento de ideias, esse processo acontecia de modo informal esporadicamente.

O último item que compõe a variável cultura de inovação, "Tomada de risco", identifica se as empresas, na busca por novas soluções, assumem riscos de forma calculada. No nível mais baixo, os gestores concordam que os riscos assumidos são calculados apenas de forma eventual, restringindo-se a alta liderança. No nível mais alto, por outro lado, esse processo acontece de maneira sistemática em todos os níveis organizacionais, baseando-se em regras preestabelecidas de autonomia. Em relação aos itens anteriores, observa-se um panorama mais positivo, pois a média esteve situada em 4,3, correspondendo a um nível intermediário. Por outro lado, o progresso obtido após a execução do projeto mostrou-se discreto.

$$
\text { Gráfico } 1 \text { - Cultura de Inovação }
$$




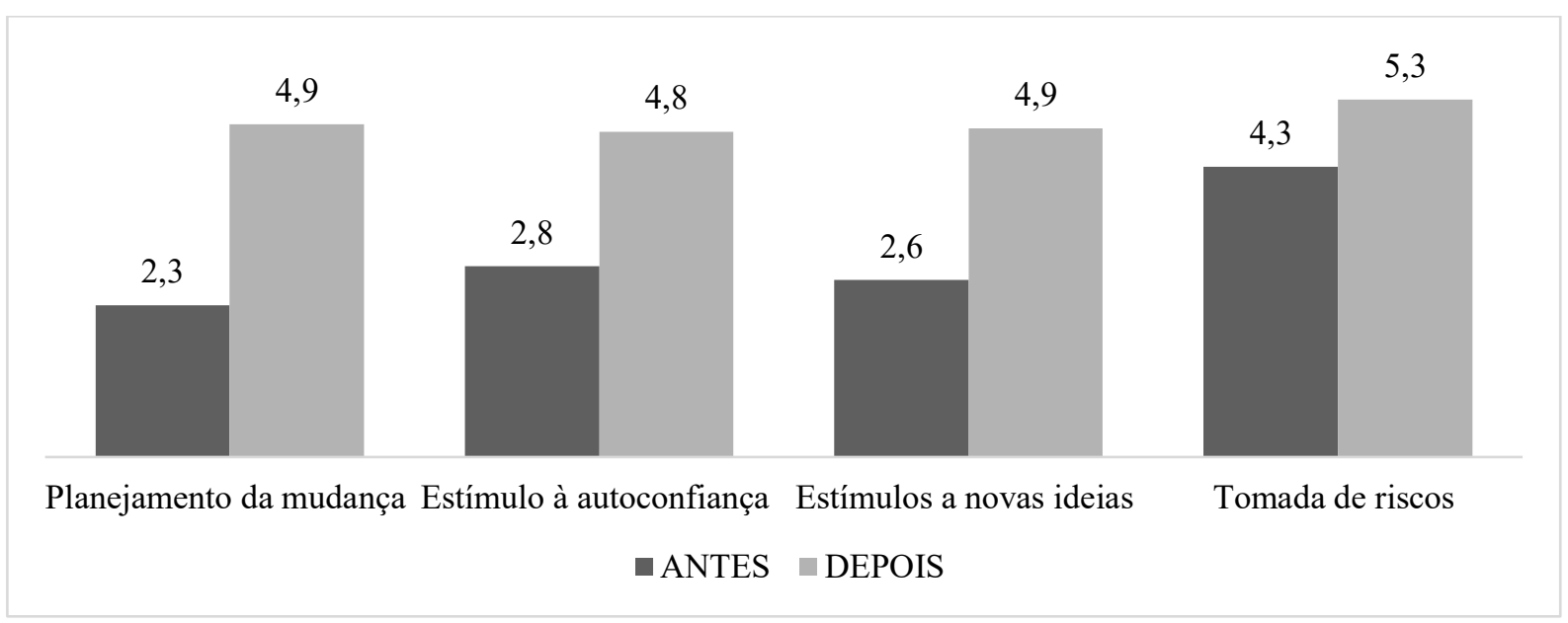

Fonte: Elaborado pelos autores (2019).

\section{b) Aprendizagem organizacional}

A aprendizagem organizacional tem relação com a competência empresarial de processar, interpretar e manusear informações e conhecimentos de modo premeditado e direcionado. Os resultados podem ser visualizados no gráfico 2 .

O item "Acesso ao conhecimento" verifica se a empresa fornece para seus funcionários acesso ao conhecimento necessário à realização de algo novo. As empresas situadas no nível mais baixo disponibilizam esse acesso apenas de maneira informal, ao contrário daquelas no nível mais alto que dispõem de um sistema institucional de gestão do conhecimento.

O nível em que as indústrias pesquisadas se situavam, antes de iniciar sua participação no projeto, era o intermediário. O panorama era representado pela ausência de um sistema próprio para a gestão do conhecimento, mas composto por práticas importantes a exemplo da participação em feiras concernentes ao setor e posterior compartilhamento do conhecimento adquirido com os colaboradores.

Diante da situação identificada, observaram-se oportunidades para propor melhorias na formalização dos procedimentos de registro e de compartilhamento do conhecimento. Assim, ainda que discretamente, foi possível obter um progresso para esta variável com elevação da média em 0,9 ponto.

Assim como no item anterior, as empresas, neste item, estavam situadas no nível intermediário. Esse fato é positivo, pois o aprendizado contínuo é um fator de competitividade importante, especialmente, em ambientes cada vez mais dinâmicos que exigem estratégias e soluções adequadas às mudanças impostas pelo mercado.

O avanço de 1,5 ponto na média foi obtido a partir do desenvolvimento de atividades, mediante o projeto de $\mathrm{Gl}$, que tinham por finalidade buscar as estratégias mais adequadas ao perfil da empresa para monitorar, por meio de gestores e colaboradores, as mais variadas fontes de conhecimentos, tais como concorrentes, clientes, mercado, ambiente, produtos, tecnologias, fornecedores, fontes de financiamento, especialistas e feiras.

No item "Revisão dos projetos", as condições em que a empresa costuma analisar e revisar seus projetos são avaliadas. $O$ nível mais baixo é compreendido pelas indústrias que concordam ter sua revisão realizada informalmente apenas quando surgem problemas. Já no nível mais alto, concordam que a revisão acontece de modo integrado ao portfólio, empregando técnicas e ferramentas de análise de cronograma, custos, qualidade e riscos.

A média de 3,2 indicou o posicionamento das indústrias pesquisadas no nível intermediário. No processo de revisão dos projetos, quando realizado, normalmente eram empregados indicadores básicos como lucratividade, eficácia e custos. Já no segundo momento da pesquisa, as empresas obtiveram um progresso de 2 pontos na média. Observou-se a importância de fomentar a elaboração de projetos de maneira organizada e formal, sendo assim seria possível avançar na revisão para que não acontecesse somente após o aparecimento de problemas. 
De todos os itens que compõem a variável aprendizagem organizacional, a "Gestão de ativos intelectuais" foi o que obteve, inicialmente, a menor média e única situada no nível baixo. No âmbito das indústrias pesquisadas, trata-se de uma atividade em que os gestores possuem relativa maturidade e desconhecem a importância, das inovações concebidas internamente.

\section{Gráfico 2 - Aprendizagem organizacional}

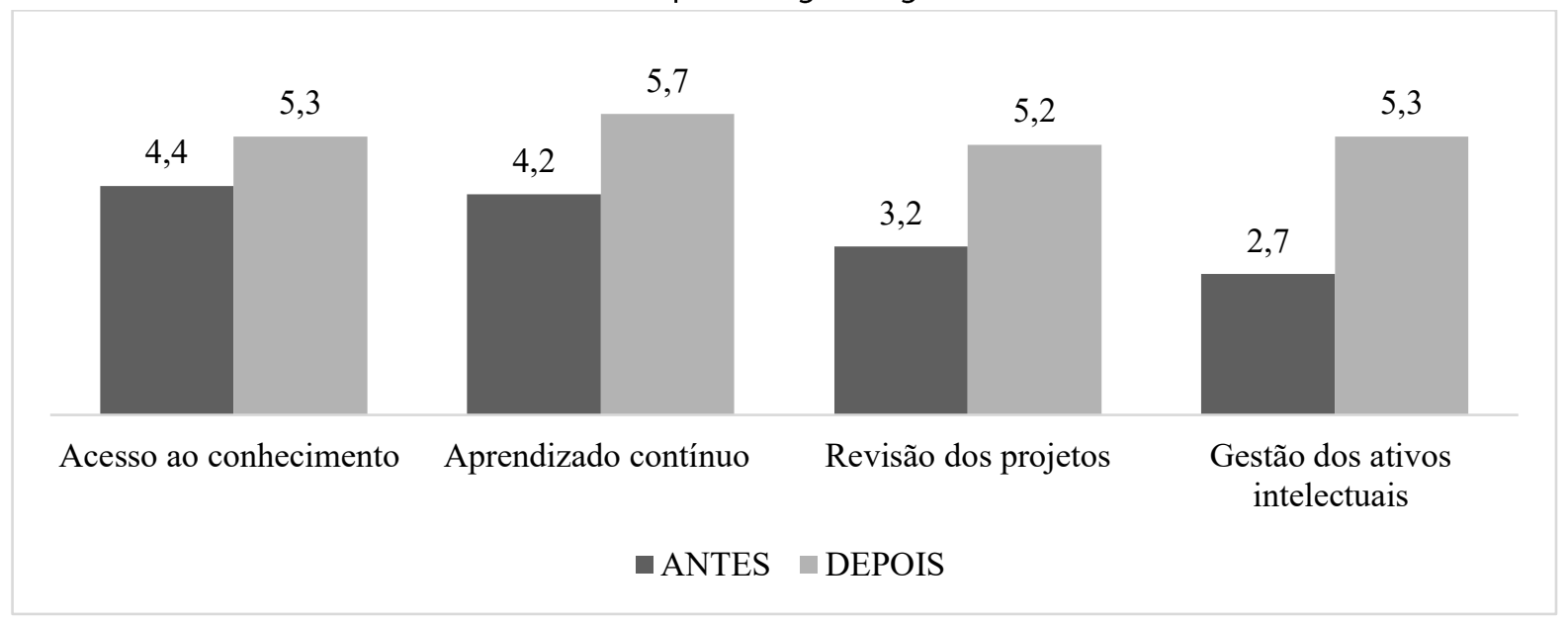

Fonte: Elaborado pelos autores (2019)

\subsubsection{Demanda}

\section{a) Marketing para a inovação}

A variável "Marketing para a inovação" foi analisada a partir dos itens: a) estudo e conhecimento do ambiente, b) oferta de valor, c) lançamento de novos produtos e d) capacidade de resposta ao mercado. Os resultados podem ser observados no gráfico 3.

O primeiro item da variável "Demanda", "Estudo e conhecimento do ambiente", identificou se as empresas coletam informações sobre mudanças no mercado, nas ações dos concorrentes e nas atitudes dos clientes. As empresas situadas no nível mais baixo da escala coletam essas informações apenas ocasionalmente, em decorrência de resultados adversos. Aquelas situadas no nível mais alto, por outro lado, buscam subsídios de forma sistemática, empregando métodos para transformá-las em estratégias de negócios.

As indústrias pesquisadas apresentaram para este item, no momento que antecede o desenvolvimento do projeto, desempenho intermediário com média de 4,9. Trata-se de um bom resultado, pois sugere que a importância do conhecimento sobre o ambiente no qual a instituição está inserida é percebida.

Além disso, identificou-se o uso contínuo de ferramentas como o benchmarking, na busca de casos de sucesso que pudessem ser adaptados para a realidade dessas indústrias, e o mapeamento de fontes de informações (sites, blogs, redes sociais, concorrentes, feiras do setor e eventos) de modo a obter dados relevantes ao desenvolvimento e aperfeiçoamento das atividades da empresa.

A realização do projeto de Gl possibilitou um progresso de 1,4 pontos na média desse item. As indústrias foram estimuladas a adotar métodos que permitissem transformar o conhecimento adquirido em estratégias de negócios. Nesse sentido, o registro formal impede que informações sejam esquecidas ou perdidas, e o compartilhamento desse com outros colaboradores corrobora para o surgimento de novas ideias e sua implementação de maneira organizada.

Para analisar a capacidade da empresa de identificar e ponderar novas exigências e preferências de clientes atuais e potenciais, empregou-se o item "Oferta de valor". As empresas que realizavam o mapeamento dessas exigências e preferências de modo eventual e sem um método estruturado estão inseridas no nível 
mais baixo. Mas quando o mapeamento foi realizado sistematicamente, a partir de processos e de práticas de gestão para transformá-las em oferta de valor, a empresa situou-se no nível mais alto.

Observou-se, inicialmente, que as indústrias tinham disponíveis ferramentas com a finalidade de identificar a opinião e as preferências de seus clientes, a exemplo da pesquisa de satisfação e dos canais digitais (site institucional, redes sociais e aplicativo).

A participação no projeto de Gl permitiu o progresso das indústrias em 1,7 pontos na média, correspondendo ao nível alto. Além do fomento ao registro das informações adquiridas no contato com o cliente, a aplicação de ferramentas como o "Business Model Canvas" possibilitou uma ampla visualização de cada ideia, bem como da viabilidade de sua transformação em oferta de valor.

O item "Lançamento de novos produtos" permitiu identificar se as empresas eram capazes de lançar novos produtos (bens ou serviços) empregando ações de marketing. As práticas eventuais e realizadas de maneira desestruturada caracterizam as organizações situadas no nível mais baixo. Em contrapartida, as empresas localizadas no nível mais alto se caracterizam por adotar práticas sistemáticas, visando seu melhor aproveitamento competitivo.

A pesquisa realizada no momento inicial apontou que as indústrias se encontravam no nível intermediário em termos de maturidade para o lançamento de novos produtos. O processo normalmente acontecia com algum grau de estruturação, empregando ações de marketing, porém, era realizado ainda de forma eventual. Nesse contexto, identificou-se como oportunidade a elaboração de um cronograma anual para o planejamento organizado das ações de marketing. Assim, obteve-se um crescimento de 1,9 pontos na média.

Gráfico 3 - Marketing para a inovação

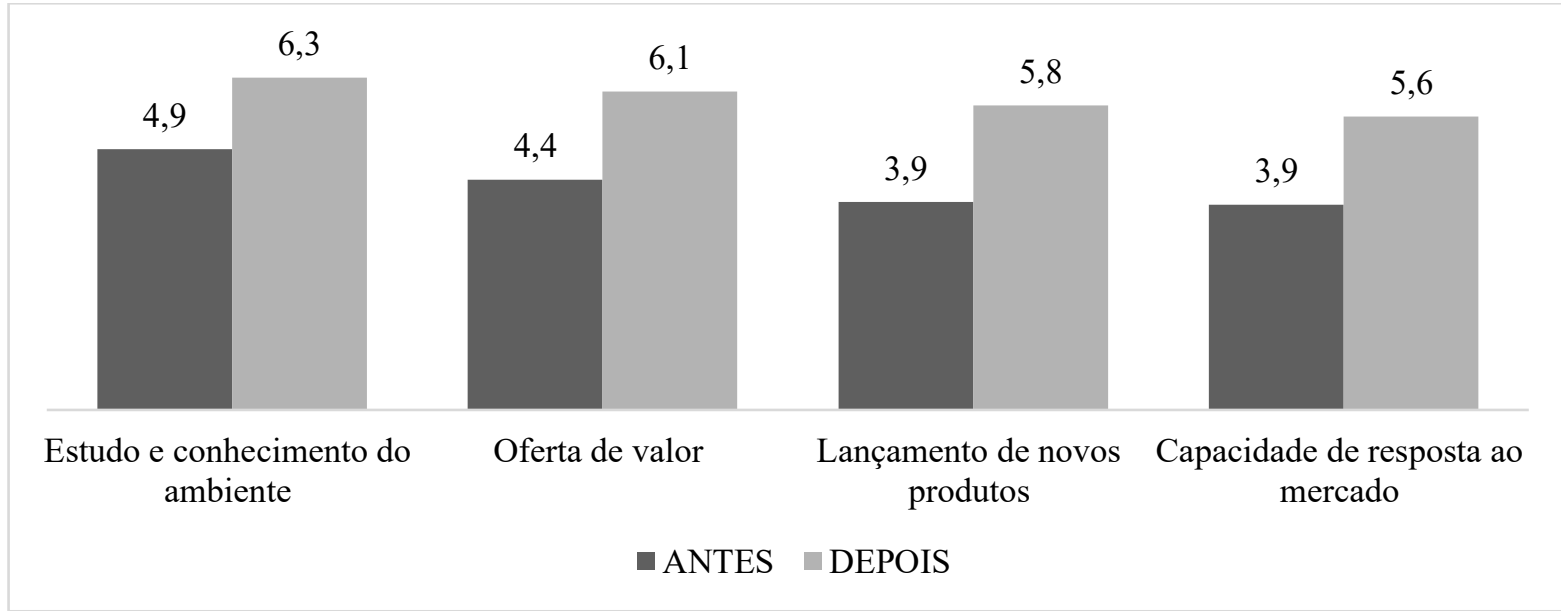

Fonte: Elaborado pelos autores (2019)

O último item teve por objetivo analisar se a empresa estava apta para responder ao lançamento de novos produtos (bens ou serviços) pela concorrência, trata-se da "Capacidade de resposta ao mercado". O nível mais baixo da escala esteve composto por indústrias com capacidade reativa desestruturada e tardia. No nível mais alto, essa competência é exercida de forma ágil e sistemática, garantindo manutenção da posição competitiva desejada.

Cabe destacar o papel do item "Estudo e conhecimento do ambiente" para a inciativa das empresas nas respostas às demandas advindas do mercado. Dessa forma, observa-se que a média inicial obtida para este item foi compatível com aquela adquirida no item "Estudo e conhecimento do ambiente", as indústrias pesquisadas mantiveram-se no nível intermediário em ambos, passando ao nível alto mediante as atividades desenvolvidas durante a execução do projeto de $\mathrm{Gl}$. 


\subsubsection{Interações com outras empresas}

\section{a) Relacionamento com o ambiente externo}

Esta variável é compreendida pelos seguintes itens: a) abertura externa; b) participação dos clientes no desenvolvimento; c) relacionamento com fornecedores; e d) atuação em redes de conhecimento externas. Os resultados podem ser observados no gráfico 4.

O item "Abertura externa" permitiu verificar se as empresas compartilhavam conhecimentos com o ambiente externo (fornecedores, clientes, outras empresas, consultores, universidades, instituições de pesquisa). No nível mais baixo, localizam-se as empresas que realizam essa troca de experiências apenas de modo eventual e informal. No nível mais alto, situam-se as empresas que realizam o compartilhamento de conhecimento de maneira sistemática, empregando o modelo de inovação aberta.

No momento inicial, os dados apontavam o posicionamento das indústrias no nível intermediário com média 4,5. Essa realidade corresponde ao fato de os gestores entenderem a importância não só de buscar apoio externo quando necessário, mas também de compartilhar ideias e criações quando estas, ao invés de serem descartadas por não servirem, podem ser úteis para outras empresas. Nesse sentido, identificou-se a atuação contínua das indústrias no compartilhamento de conhecimentos mediante reuniões sindicais, eventos, recebimento de visitas de instituições de ensino e relações mais próximas com clientes ou fornecedores. A partir da disseminação do conceito de inovação aberta obteve-se um progresso na média que saiu do nível intermediário para o nível alto.

O segundo item, "Participação dos clientes no desenvolvimento", analisou se havia o envolvimento dos clientes no processo de desenvolvimento novos produtos (bens ou serviços) ou melhorias. As empresas possuíam relativa maturidade para esse quesito quando a participação de seus clientes nesse tipo de atividade, pois acontecia somente de modo eventual e sem métodos específicos, ou seja, situam-se no nível mais baixo. Por outro lado, as empresas que detêm modelos sistemáticos e cooperativos de criação junto aos clientes estão inseridas no nível mais alto.

A partir da pesquisa realizada no momento anterior ao desenvolvimento do projeto de Gl, observouse que as sugestões e opiniões dos clientes eram, eventualmente e com métodos específicos, objetos de análise para fins de implementação de melhorias seja nos produtos, serviços ou na empresa como um todo. Por outro lado, o envolvimento dos clientes no processo de desenvolver novos produtos estava presente somente em parte das indústrias. Assim, identifica-se uma média de 4,1 correspondente ao nível intermediário.

Para as empresas que já usufruíam desta atividade, buscou-se aperfeiçoar os modelos já existentes. Nesse sentindo, foi possível obter um progresso de 1,5 pontos na média após a finalização do projeto. 0 compartilhamento de informações da empresa com seus fornecedores foi analisado mediante o terceiro item: "Relacionamento com fornecedores". As empresas situadas no nível mais baixo trocam experiências informalmente, já aquelas inseridas no nível mais alto usufruem de bons relacionamentos para processos conjuntos de desenvolvimento, normalmente realizado sistematicamente.

\section{Gráfico 4 - Relacionamento com o ambiente externo}

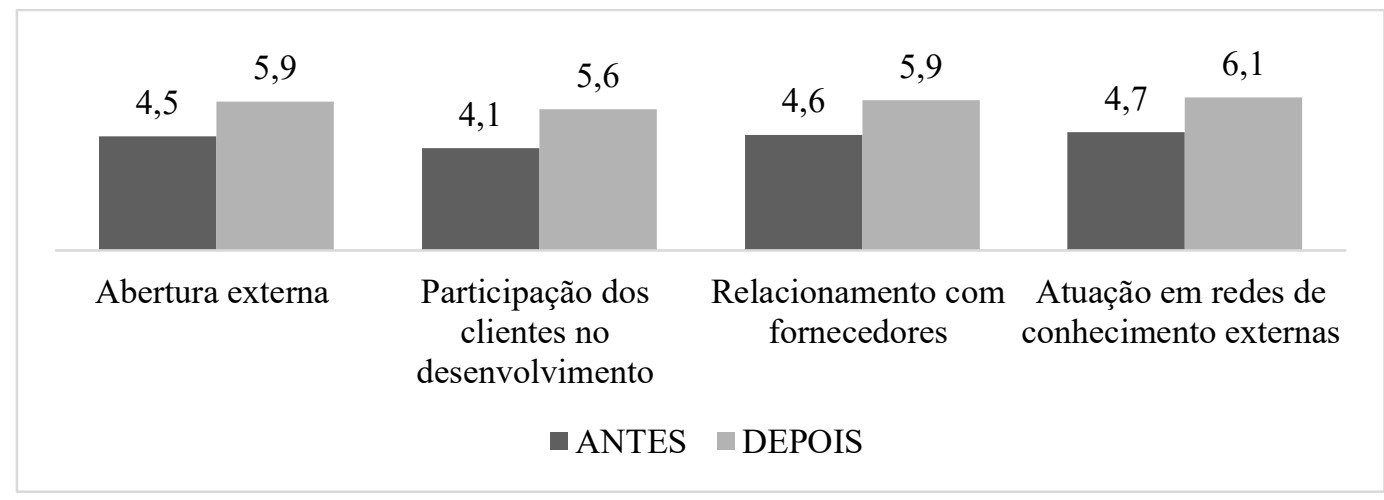

Fonte: Elaborado pelos autores (2019) 
O desempenho observado para o relacionamento das indústrias com seus fornecedores esteve no nível intermediário, assim como o item anterior. Primeiramente, nota-se que os gestores em sua maioria mantêm relações de troca contínua de conhecimento que vai além do poder de barganha, envolve informações sobre materiais e novas tecnologias, capacitações para colaboradores sobre os produtos adquiridos pela organização, bem como formação de redes de indústrias do mesmo setor para melhor articulação. Trata-se de uma realidade positiva, pois os fornecedores são parceiros importantes na inovação. No segundo momento da pesquisa, após a execução do projeto, esse cenário demonstra progressos a partir do crescimento de 1,3 pontos na média.

Por fim, o item "Atuação em redes de conhecimento externas" verificou se as empresas, para desenvolver seus conhecimentos ou competências, estabeleciam relações com outras empresas, associações industriais, consultores, universidades e centros de pesquisa. Nas organizações inseridas no nível mais baixo, essas relações se dão de forma eventual e informal. Naquelas situadas no nível mais alto, as articulações acontecem sistematicamente, integrando-se formalmente a redes e grupos de cooperação para a inovação. $O$ cenário inicial identificado nas indústrias pesquisadas apontou um nível de maturidade intermediário para a atuação em redes externas.

\subsection{Maturidade das empresas industriais na GI}

O teste não paramétrico Wilcoxon foi utilizado neste estudo com o objetivo de identificar se existia diferença estatística significativa entre as duas condições - antes do desenvolvimento do projeto (T0) e após a conclusão de sua execução (T1) - para cada uma das variáveis discutidas anteriormente. Nesse sentido, foram estabelecidas as hipóteses nulas e alternativa a seguir: H0 - condições não se diferem em termos de maturidade na Gl e $\mathrm{H} 1$ - condições se diferem em termos de maturidade na Gl-

Partiu-se do pressuposto de que o grupo de indústrias alagoanas, quando comparado ambos os momentos, teria maturidade em termos de Gl distintas em função de sua participação no projeto - valor estatisticamente significativo associado a um nível de probabilidade de $p<0,05$. Na tabela 1, é possível observar os parâmetros utilizados para analisar as diferenças entre os valores obtidos para o grupo de empresas em ambos os momentos. Nela são apresentadas as médias e seus respectivos desvios-padrão (DP), o tamanho total do grupo (N), o escore z e o valor da significância (p).

Tabela 1 - Teste de hipóteses para as variáveis da Gl

\begin{tabular}{lccccccc}
\hline Variáveis & \multicolumn{3}{c}{ Antes } & \multicolumn{2}{c}{ Depois } & \multicolumn{3}{c}{ estatísticas } \\
\cline { 2 - 8 } & Média & DP & Média & DP & N & z & $\mathrm{p}$ \\
\hline Cultura de inovação & 3,04 & 0,7720 & 5,02 & 1,0277 & 19 & $-3,830$ & $0,000^{* *}$ \\
Aprendizagem organizacional & 3,64 & 0,7042 & 5,41 & 0,8987 & 19 & $-3,728$ & $0,000^{* *}$ \\
Marketing para a inovação & 4,12 & 0,9194 & 5,95 & 0,7081 & 19 & $-3,730$ & $0,000^{* *}$ \\
Relacionamento com o ambiente & 4,48 & 0,9311 & 5,88 & 0,7164 & 19 & $-3,830$ & $0,000^{* *}$ \\
externo & & & & & & & \\
\hline *
\end{tabular}

Fonte: Elaborado pelos autores (2019)

Os resultados da análise do desenvolvimento do projeto de Gl, quando submetidos ao teste de Wilcoxon, permitiram identificar mudança no ambiente das indústrias. O grupo exibiu diferença significativa entre os momentos pré e pós-projeto, em todas as variáveis $(p<0,05)$. Estes resultados assinalam que a participação no Projeto de Gestão da Inovação para Micro e Pequenas Empresas Industriais possibilitou avanço na maturidade das organizações quanto a Gl. Portanto, com base nessas constatações, se rejeita a hipótese nula previamente formulada, pois as indústrias participantes do projeto apresentaram amadurecimento em suas atividades habituais no aspecto da inovação. 


\subsection{Análise da relação entre a $\mathrm{Gl}$ e $\mathrm{o}$ uso de instrumentos de políticas públicas de CT\&I.}

A partir da análise dos documentos descritos na metodologia, identificou-se o total de doze instrumentos no Estado, entre subvenção econômica, financiamento e concessão de bolsas (figura 3). No Estado, há a predominância de instrumentos de financiamento, tipo utilizado na obtenção de recursos reembolsáveis. Mediante análise, percebe-se a limitação da oferta de financiamentos para atividades de inovação à Finep e ao BNDES. Já no apoio à captação de recursos humanos, há o predomínio do CNPq, enquanto agência de fomento responsável. Esse tipo de recurso, assim como o recurso não reembolsável (subvenção econômica) são disponibilizados no Estado em quantidade relativamente baixa, quando comparados ao financiamento reembolsável.

Figura 2 - Instrumentos de políticas públicas de CT\&I disponíveis em Alagoas

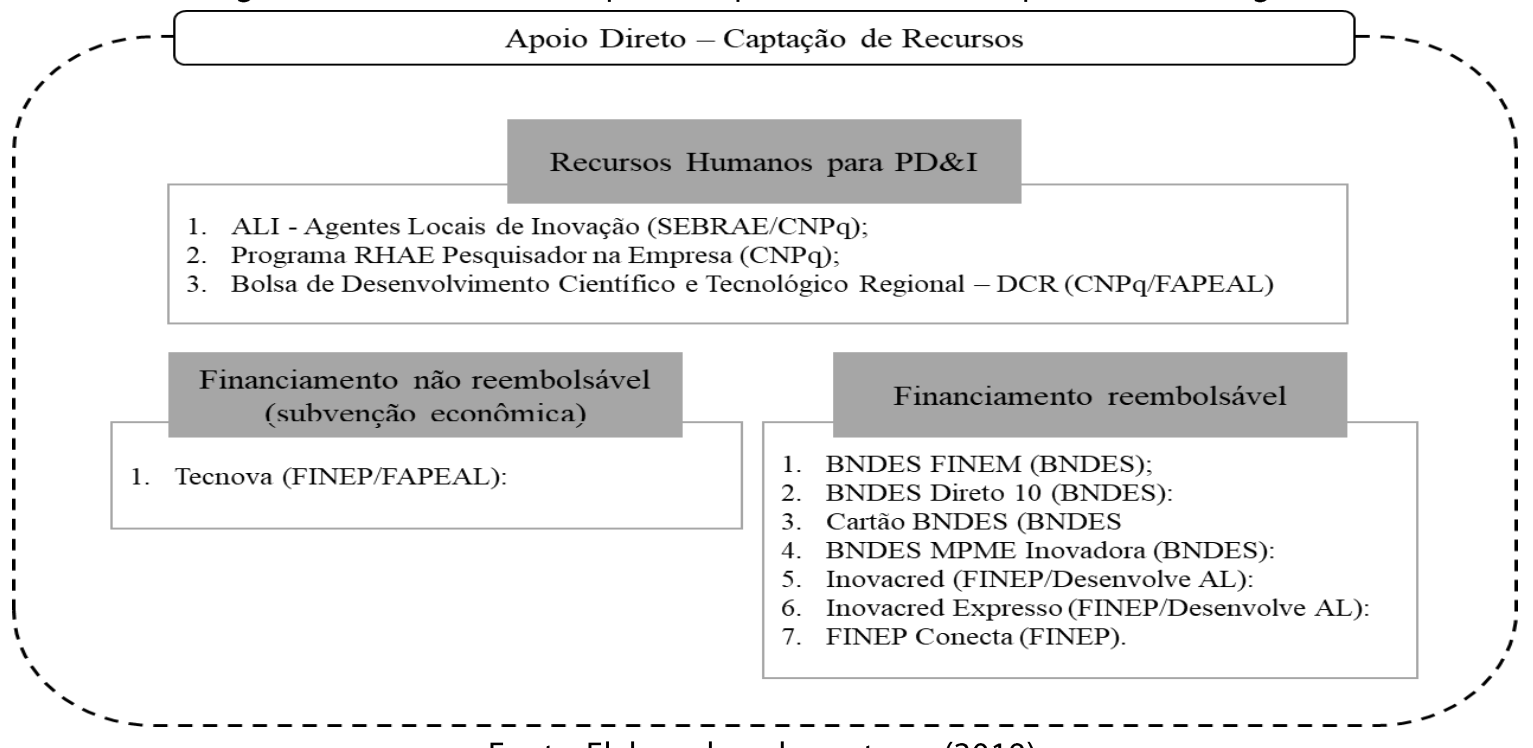

Fonte: Elaborado pelos autores (2019).

A partir da aplicação do segundo formulário foi possível constatar que, do total das dezenove empresas pesquisadas, apenas três utilizaram algum dos instrumentos mencionados. Trata-se de um dado importante, pois aponta a fragilidade do acesso empresas aos instrumentos.

Uma empresa obteve recursos de subvenção econômica decorrente de dois editais. O primeiro lançado no ano de 2011, referente ao Programa PAPPE Integração (dez empresas contempladas); o segundo, em 2013, referente ao Programa TECNOVA (treze empresas contempladas), ambos liderados pela FINEP com o apoio da Fundação de Apoio de Pesquisa do Estado de Alagoas.

As outras duas empresas participaram do Programa ALI que em 2010 alcançou abrangência nacional graças à parceria do Sebrae firmada com a CNPq. Cabe destacar que o ALI é o único programa, entre os instrumentos de políticas públicas disponíveis em Alagoas, direcionado a desenvolver ações específicas voltadas à inserção da cultura da inovação nas organizações.

De modo geral, constata-se que há uma relação indireta entre o acesso a instrumentos de políticas públicas e a Gl nas empresas à medida que 0 acesso contribuiu para o surgimento de comportamentos inovadores, mas esteve distante de viabilizar uma gestão da inovação contínua no interior das empresas. No momento inicial do projeto de $\mathrm{Gl}$, foi identificado que as indústrias desenvolveram, ainda que com recursos próprios, inovações importantes nos anos posteriores do acesso ao programa, porém o desconhecimento sobre os conceitos de inovação e outras oportunidades que envolvem o tema ainda estiveram presentes. Além disso, as ações eram desenvolvidas de forma pouco sistêmica (carente de processos estruturados e registrados), criando obstáculos no gerenciamento da implantação das ideias.

Ademais, cabe destacar os pontos comuns percebidos nas três indústrias: perfil inovador dos gestores; forte relacionamento com o ambiente externo, envolvendo fornecedores, clientes e concorrentes; e forte 
aproximação com instituições do Sistema S - Sesi, Senai e Sebrae. Assim, é possível estabelecer um perfil de negócio com tendências ao uso de instrumentos voltados à inovação. No que tange ao acesso direto a instrumentos de políticas públicas para captação de recursos, verifica-se que ainda é incipiente no cenário do estado de Alagoas.

\section{CONCLUSÃO}

O estudo teve por objetivo analisar a relação entre o uso de instrumentos de políticas públicas de inovação e a Gestão da Inovação (GI) no setor industrial do estado de Alagoas. Especificamente, almejou analisar o desempenho das indústrias em relação ao desenvolvimento de uma metodologia de $\mathrm{Gl}$, examinar a maturidade de empresas industriais quanto às práticas de Gl e mapear os instrumentos de políticas públicas acessados por essas indústrias. A análise do objetivo da pesquisa permitiu diagnosticar a maturidade de inovação das empresas industriais alagoanas nos momentos do projeto nos períodos do T0 e T1.

Assim, pode-se ilustrar que maioria das empresas não utilizava ou tinha desconhecimento das práticas estabelecidas no momento T0. Alguns gestores não tinham acesso ou não aplicavam as ferramentas de forma ampla e contínua, o que dificultava um bom gerenciamento da inovação. A partir da orientação recebida durante o período do projeto, as empresas adquiriram maturidade que seria necessária à aplicação de método e práticas especificas de Gl à medida que se rejeitou a hipótese nula previamente formulada, pois as indústrias participantes do projeto apresentaram amadurecimento em suas atividades habituais no aspecto inovação.

Em especial, diante dos resultados obtidos foi verificado evolução da maturidade no tocante às práticas de gestão da inovação. Constatou-se, ainda, que o projeto contribuiu para o entendimento da importância da $\mathrm{Gl}$, visto que as atividades desenvolvidas corroboraram para a disseminação da cultura da inovação e as atividades colaborativas ajudaram participantes a compreenderem a relevância das parcerias e do envolvimento dos colaboradores nos processos criativos.

Além disso, mapearam-se o total de doze instrumentos distribuídos nos tipos subvenção econômica, financiamento e concessão de bolsas, sendo o financiamento o instrumento predominante. Sobre o acesso das indústrias a esses instrumentos, os resultados apontaram que, do total das dezenove empresas participantes apenas três utilizaram instrumentos mencionados no mapeamento, logo sendo débil o acesso das empresas alagoanas a esses tipos de benefícios.

Ademais, sobre a análise da relação entre o acesso a instrumentos de políticas públicas de $\mathrm{CT} \& \mathrm{l}$ e a Gl, constatou-se que há uma relação indireta entre o acesso a instrumentos de políticas públicas e a Gl nas empresas à medida que o acesso contribuiu para o surgimento de comportamentos inovadores, mas esteve distante de viabilizar uma gestão da inovação contínua no interior das empresas.

Em adição, entre as limitações do trabalho, destaca-se o pequeno número de empresas participantes do projeto e a dificuldade das empresas em disponibilizar as informações, o que resultou em tempo maior da aplicação dos questionários nos períodos dos T0 e T1 que pode ter minimizado os resultados. Contudo, através das informações obtidas, percebeu-se a necessidade de maior investimento em políticas que incentivem a cooperação e fortalecimento do ecossistema de inovação na indústria de Alagoas.

Por fim, os resultados não apontaram conclusões definitivas, mas a necessidade de continuidade das linhas de pesquisa e de outros projetos que permitam considerar a diversidade da indústria e as mutações do mercado.

\section{REFERÊNCIAS}

ANDREONI, Antonio. Structural Learning: Embedding Discoveries and the Dynamics of Production.

Structural Change and Economic Dynamics, Amsterdã, v. 29, p. 58-74, 2013.

AVELLAR, Ana P. et al. Avaliação de impacto de programas de incentivos fiscais à inovação: um estudo sobre os efeitos do PDTI no Brasil. Economia, Uberlândia, v. 9, n. 1, p. 143-164, 2008. 
AVELLAR, Ana P.; BOTELHO, Marisa R. Políticas de apoio à inovação em pequenas empresas: evidências sobre a experiência brasileira recente. Economia e Sociedade, Campinas, v. 24, n. 2, p. 379-417, ago. 2015.

BARBIERI, J. C.; ÁLVARES, A. C. T. Sixth Generation Innovation Model: Description of a Success Model. Revista de Administração e Inovação, São Paulo, v.13 , n.2 , p.88-112, abr./jun.2016.

BERKHOUT, A. J. et al. Innovating the innovation process. International Journal of Technology Management, Erlangen, v. 34, n. 3-4, p. 390-404, 2006.

BISNETO, José P. M.; LINS, Olga B. S M. Gestão da inovação: uma aproximação conceitual. Revista Brasileira de Gestão e Inovação, Cruz das Almas, v. 3, n. 2, p. 86-109, 2015.

BORRÁS, Susana; EDQUIST, Charles. The Choice of Innovation Policy Instruments. Technological Forecasting and Social Change, Frederiksberg, v. 80, n. 8, p. 1513-1522, 2013.

BRASIL. Lei no 10.973, de 2 de dezembro de 2004. Dispõe sobre incentivos à inovação e à pesquisa científica e tecnológica no ambiente produtivo e dá outras providências. Brasília, DF: Presidência da República, [2004] Disponível em: http://www.planalto.gov.br/ccivil_03/_ato2004-2006/2004/lei/l10.973.htm. Acesso em: 5 jun. 2018.

BRASIL. Lei no 13.243, de 11 de janeiro de 2016. Dispõe sobre estímulos ao desenvolvimento científico, à pesquisa, à capacitação científica e tecnológica e à inovação e altera a Lei no 10.973, de 2 de dezembro de 2004, a Lei n 6.815, de 19 de agosto de 1980, a Lei n 8.666, de 21 de junho de 1993, a Lei no 12.462, de 4 de agosto de 2011, a Lei no 8.745, de 9 de dezembro de 1993, a Lei no 8.958, de 20 de dezembro de 1994, a Lei ${ }^{\circ}$ 8.010, de 29 de março de 1990, a Lei no 8.032, de 12 de abril de 1990, e a Lei no 12.772, de 28 de dezembro de 2012, nos termos da Emenda Constitucional n 85, de 26 de fevereiro de 2015. Brasília, DF: Presidência da República, [2016]. Disponível em:http://www.planalto.gov.br/ccivil_03/_ato2004-2006/2004/lei/l10.973.htm. Acesso em: 5 jun. 2018.

CALANTONE, R. J.; CAVUSGIL, S. T.; ZHAO, Y. Learning orientation, firm innovation capability, and firm performance. Industrial Marketing Management, East Lansing, vol. 31, n. 6, p. 515-524, 2002.

CASTELA, Bernardo M. S.; FERREIRA, Fernando. A. F.; FERREIRA, João J. M.; MARQUES, Carla S. E. Assessing theinnovation capability of small-and medium-sized enterprises using anon-parametric and integrative approach. Management Decision, Lisbon, vol. 56, n. 6, p. 1365-1383, 2018.

CANONGIA, Claudia et al. Foresight, inteligência competitiva e gestão do conhecimento: instrumentos para a gestão da inovação. Gestão e Produção, São Carlos, v. 11, n. 2, p. 231-238, ago. 2004. Disponível em: http://www.scielo.br/pdf/gp/v11n2/a09v11n2.pdf. Acesso em: 24 jul. 2018.

CLARK, K. B.; WHEELWRIGHT, S. C. Revolutionizing Product Development: Quantum Leaps in Speed, Efficiency, and Quality, New York, 1992.

CNI. Cartilha: gestão da inovação. Brasília: CNI, MEl, 2010. Disponível em: http://www.ipdeletron.org.br/wwwroot/pdf-publicacoes/8/cartilha_gestao_inovacao_cni.pdf. Acesso em: 30 jul. 2018.

CNI. Desempenho do Brasil no índice global de inovação 2011-2017. Brasília: CNI, 2017. Disponível em: http://www.portaldaindustria.com.br/publicacoes/2017/8/desempenho-do-brasil-no-indice-global-deinovacao-2011-2017/. Acesso em: 9 set. 2018.

CNI. O marco legal e os gargalos da Lei n 13.243 de 2016. Brasília: CNI, 2018. Disponível em: http://www.portaldaindustria.com.br/publicacoes/2018/3/o-estado-da-inovacao-no-brasil-mei-2018-marcolegal-de-inovacao/. Acesso em: 8 set. 2018.

COADA, Alex et al. Innovation and industrial dynamics. Structural Change and Economic Dynamics, Lima, v. 50, p. 126-131, 2019. 
COOPER, R. G. Third-Generation New Product Processes. Journal of Product Innovation Management, v. 11, p. 3-14, 1994.

COOPER, R. G. Perspective: The Stage-Gate (R) idea-tolaunch process-update, what's new, and NexGen systems. Journal of Product Innovation Management, v. 25, n. 3, p. 213-232, 2008.

DANCEY, Christine P.; REIDY, John. Estatística sem matemática para psicologia. Porto Alegre: Penso, ed. 5, 2013.

DE MARTINO, M.; MAGNOTTI, F. The innovation capacity of small food firmsin Italy. European Journal of Innovation Management, vol. 21, n.3, p. 362-383, 2018.

DICKEL, Deise G.; MOURA, Gilnei L. Organizational performance evaluation in intangible criteria: a model based on knowledge management and innovation management. RAI Revista de Administração e Inovação, v. 13, n. 3, p. 211-220, 2016.

DOSI, Giovanni et al. Innovation and the evolution of firms. In: DOSI, Giovanni et al. Technical change and economic theory. Laboratory of Economics and Management (LEM), Pisa, Italy: Sant'Anna School of Advanced Studies, 1988. p. 219-308.

DOCHERTY, Michel. Primer on open innovation: principles and practice. PDMA Visions, v. 30, n. 2, p. 13-17, 2006.

DUTTA, Soumitra; LANVIN, Bruno; WUNSCH-VINCENT, Sacha. The global innovation index 2015: effective innovation policies for development. Genebra: Cornell Wuniversity, Insead e Wipo, 2015.

EDMONDSON, Duncan L.; KERN, Florian; ROGGE, Karoline S. The co-evolution of policy mixes and sociotechnical systems: towards a conceptual framework of policy mix feedback in sustainability transitions. Research Policy, v. 48, n. 10, mar. 2018.

FINEP. Fundos setoriais: O que são fundos setoriais. [2018]. Disponível em: http://www.finep.gov.br/a-finepexterno/fontes-de-recurso/fundos-setoriais/o-que-sao-fundos-setoriais. Acesso em: 10 set. 2018.

FREITAS FILHO, Fernando Luiz. Gestão da inovação: teoria e prática para implantação. Santa Catarina: Editora Atlas SA, 2013.

FREITAS FILHO, Fernando Luiz; CAMPOS, Thaise; SOUZA, João Artur de. Avaliação do grau de inovação do processo de gestão de pessoas em uma empresa fabricante de eletrodomésticos. Strategic Design Research Journal, Santa Catarina, v. 8, n. 2, 2015.

FREEMAN, C, Technology policy and economic performance: lessons from Japan, London: Pinter, 1987.

GOMES, Vanessa C. et al. Os fundos setoriais e a redefiniçao do modelo de promoção de ciência, tecnologia e inovação no Brasil: uma análise à luz do CT-Agro. Rev. Adm., São Paulo, v. 50, n. 3, p. 353-368, 2015.

JAUMOTTE, Florence; PAIN, Nigel. An overview of public policies to support innovation. Organisation for Economic Co-operation and Development, Paris, n. 456, 2005.

HAIR JR, Joseph et al. Fundamentos de métodos de pesquisa em administração. Porto Alegre: Bookman, 2005.

HANSEN, M. T.; BIRKINSHAW, J. The innovation value chain. Harvard Business Review, v. 85, n. 6, p. 121-130, 2007. 
INSTITUTO EUVALDO LODI DE SANTA CATARINA. A metodologia NUGIN de Gestão da Inovação. [2011]. Disponível em: https://www.unochapeco.edu.br/static/data/portal/downloads/1071.pdf. Acesso em: 1 set. 2019.

KANNEBLEY JR, Sergio; PORTO, Geciane. Incentivos fiscais à pesquisa, desenvolvimento e inovação no Brasil: uma avaliação das políticas recentes. São Paulo: Banco Interamericano de Desenvolvimento, 2012.

KERNA, Florian; ROGGE, Karoline; HOWLETTD, Michael. Policy mixes for sustainability transitions: New approaches and insightsthrough bridging innovation and policy studies. Research Policy, v. 48, n. 10, jul. 2019.

LAWSON, B.; SAMSON, D. Developing innovation capability inorganisations: a dynamic capabilities approach. International Journal of Innovation Management, v. 5, n. 3, p. 377-400, 2001.

LIN, H. F. Knowledge sharing and firm innovation capability: An empiricalstudy. International Journal of Manpower, v. 28, n. 3-4, p. 315-332, 2007.

LIYANAGE, Shantha; GREENFIELD, Paul F; DON, Robert. Towards a fourth generation R\&D management model-research networks in knowledge management. International journal of technology management, v. 18, n. 3-4, p. 372-393, 1999.

LUNDVALL, B. A. National systems of innovation: towards a theory of innovation and interactive learning. London: Pinter, 1992.

KAHN, Kennethe B. Understanding innovation. Business Horizons, v. 61, n. 3, p. 453-460, 2018.

MCTIC. Estratégia nacional de ciência, tecnologia e inovação 2016-2022. Brasília: MCTIC, 2016.

MILLER, William L. Innovation for Business Growth. Research-Technology Management, vol. 44, n. 5, p. 2641, 2001.

NEGRI, Fernanda. Por uma nova geração de políticas de inovação no Brasil. In: TURCHI, Lenita Maria; MORAIS, José Mauro. Políticas de Apoio à Inovação Tecnológica no Brasil: avanços recentes, limitações e propostas de ações. Brasília: Ipea, 2017. p. 25-46.

NELSON, R. National Innovation Systems: A Comparative Analysis, New York: Oxford University Press, 1993.

OECD. OECD Science, Technology and Innovation Outlook 2016. Paris: OECD Publishing, 2016.

PARANHOS, Julia; CATALDO, Bruna; PINTO, Ana Carolina A. Criação, institucionalização e funcionamento dos núcleos de inovação tecnológica no brasil: características e desafios. Revista Eletrônica de Administração, v. 24 , n. 2, p. 253-280, 2018

PALADINO, G. Introdução. In: FAYET, E. A. (org.). Gerenciar a inovação: um desafio para as empresas. Curitiba: IEL (PR), 2010. cap. 1.

PRODANOV, Cleber C.; FREITAS, Ernani C. Metodologia do trabalho científico: métodos e técnicas da pesquisa e do trabalho acadêmico. Rio Grande do Sul: Editora Feevale, 2013. 277 p.

ROGGE, K.S.; REICHARDT, K. Policy mixes for sustainability transitions: an extended concept and framework for analysis. Research Policy, v. 45, n. 8, p. 1620-1635, 2016.

SALERNO, Mario S.; KUBOTA, Luis C. Estado e inovação. In: SALERNO, Mario S.; KUBOTA, Luis C. Políticas de inventivo à inovação tecnológica no país. Brasília: Ipea, 2008. p. 13-64. 
SANTA RITA, Luciana, P.; FERREIRA JUNIOR. F, J; SÁ, Eliana, M. O. Estimativa do índice de competitividade da indústria: o caso de Alagoas. RAI - Revista de Administração e Inovação, v. 10, n. 4, p. 136-163, 2013.

SCHUMPETER, A Joseph. Teoria do desenvolvimento econômico. São Paulo: Abril Cultural, 1982.

SAUNILA, Minna. Innovation capability in SMEs: A systematic review of the literature. Journal of Innovation \& Knowledge, 2019.

SCHOT, J.; STEINMUELLER, W. E. Three frames for innovation policy: R\&D, systems of innovation and transformative change. Research Policy, v. 47, n. 9, p. 1554-1567, 2018.

TEZA, Pierry et al. Ideias para a inovação: um mapeamento sistemático da literatura. Gest. Prod., São Carlos, v. 23, n. 1, p. 60-83, 2016. Disponível em: http://www.scielo.br/pdf/gp/v23n1/en_0104-530X-gp-0104530X1454-14.pdf. Acesso em: 12 mar. 2018.

TIDD, Joe; BESSANT, John. Gestão da inovação. Porto Alegre: Bookman, 2015, ed. 5.

TIDD, Joe; BESSANT, John; PAVITT, Keith. Managing innovation integrating technological, market and organizational change. England: John Wiley and Sons Ltd, 2008.

TIGRE, P. B. Gestão da Inovação: a economia da tecnologia no Brasil. Rio de Janeiro: Elsevier, 2006.

TURCHI, Lenita M.; MORAIS, José M. Políticas de apoio à inovação tecnológica no Brasil: avanços recentes, limitações e propostas de ações. Brasília: Ipea, 2017.

ZAWISLAK, P. A. et al. Types of innovation in low-technology firms of emerging markets: an empirical study in Brazilian Industry. Revista de Administração e Inovação, 10, n. 1, p. 212-231, 2013.

ZEN, Aurora Carneiro et al. Rota da inovação: uma proposta de metodologia de gestão da inovação. Revista de administração contemporânea. vol. 21, n. 6, p. 875-892, 2017.

ZHENG, Y., LIU, J.; GEORGE, G. The dynamic impact of innovative capabilityand inter-firm network on firm valuation: A longitudinal study ofbiotechnology start-ups. Journal of Business Venturing, v. 25, n. 6, p. 593$609,2010$.

WIECZOREK, Anna J.; HEKKERT, Marko P. Systemic instruments for systemic innovation problems: a framework for policy makers and innovation scholars. Science and Public Policy, v. 39, n. 1, p. 74-87, 2012. 